\title{
EL SENTIMIENTO DEL EXILIO EN DOS POETAS ALEJADOS DE SU PATRIA: EL DUQUE DE RIVAS Y VÍCTOR HUGO
}

Brigitte Leguen

$U N E D$

Cada escritor, cada poeta, que en un momento determinado de su existencia ha vivido la dolorosa experiencia del exilio y ha intentado expresar a través de su obra la condición del proscrito, de «el que sale» sin ninguna promesa de regreso, vuelve a repetir, conscientemente o no, los gestos y el discurso de otros exiliados pertenecientes a otro tiempo y a otro lugar. Como dijo Saint John Perse «l'exil vient de loin» y si existe un «estado de exilio" existe igualmente un discurso del exilio que se remonta históricamente a la antigüedad ${ }^{\prime}$.

Recordemos una vez más el carácter a la vez universal y local de la obra de arte. El poeta exiliado, sea griego, español o francés, vive una experiencia y produce una obra que es la de la separación. Lo que produce y lo que recibimos va más allá del espacio, del tiempo y de los límites impuestos por su experiencia personal, aunque el punto de arranque dependa estrechamente de un marco y de un momento de la historia que constituyen la primera realidad del proceso de creación antes de llegar al amalgama de una forma y de una experiencia (véase lo que dice sobre ello Jean Rousset) ${ }^{2}$. Compartimos con Octavio Paz la opinión según la que «la obra es una forma que se desprende del suelo y no ocupa lugar en el espacio; es una imagen.

La primera obra conocida escrita en Occidente sobre el exilio se debe a Aristipo de Cirene, nacido hacia 435 antes de Cristo y que fue discípulo de Sócrates. Diógenes Laercio nos da el título de la obra: a los exiliados. Algunos siglos más tarde, Plutarco escribre su tratado sobre el exilio. Recordemos también entre los exiliados que son a la vez escritores a Ovidio autor de Los Tristes.

2 Jean Rousset, Forme et signification, París, José Corti, 1963: «L'épanouissement simultané d'une structure et d'une pensée, l'amalgame d'une forme et d'une expérience dont la genèse et la croissance sont solidaires». 
Sólo que la imagen cobra cuerpo porque está atada a un suelo y a un momento».

Víctor Hugo y el duque de Rivas conocieron los dos las angustias del destierro. Los dos participaron en la vida política de sus respectivos países. Son poetas y hombres de acción a la vez y opinan que el hombre de Letras debe intervenir y participar. Los dos conocen la censura y el exilio político, impuesto por Napoleón III y Fernando VII respectivamente.

Existe entre estos dos hombres un desplazamiento en el tiempo que implicará importantes diferencias formales y temáticas, aunque la trayectoria será en muchos puntos parecida como veremos a continuación.

El duque de Rivas deja España en 1823 y se queda once años lejos de su patria; durante este tiempo reside en Londres, Malta y París. Víctor Hugo recibe su orden de expulsión en 1852 y se establece primero en Jersey y luego en Guernesey. Su destierro dura hasta el año 1870. Las diferencias en ambos casos son notables; cuando Angel de Saavedra regresa a España en 1833, Víctor Hugo todavía no ha vivido la ruptura con su tierra natal. Mientras Víctor Hugo es claramente un romántico el duque de Rivas está todavía, durante la época de su exilio, en la bisagra del Neoclasicismo aunque se le considere, junto con José de Espronceda y José Zorrilla, como uno de los tres grandes precursores de la poesía romántica en España ${ }^{3}$.

Víctor Hugo, muy próximo a la cincuentena, vive un segundo nacimiento y prepara, en su isla rodeada de silencio y en la que se impone «le tutoiement avec la sombre solitude» su gran poesía del yo ${ }^{4}$. En cuanto al duque de Rivas, se sacude el rígido corsé de la censura, cambia de sensibilidad y de actitud frente a la condición humana y descubre nuevas fórmulas literarias.

Digamos que Hugo llega al exilio ya como romántico y tiende a rematar una metamorfosis ya iniciada, mientras que Rivas llega tomando el pulso de un mundo que descubre, con lo que el exilio cobra sentido y el poeta accede a lo que podemos llamar el estado de exilio ${ }^{5}$.

Los textos nos muestran los rasgos comunes que unen a estos dos poetas

3ara definir los términos de Neoclasicismo y Prerromanticismo hemos consultado el libro de Joaquín Arce, La poesía del siglo ilustrado, Madrid, Alhambra, 1981.

${ }_{4}^{4}$ Pierre Albouys, edición y notas de Oeuvres Poétiques de Víctor Hugo, tomo II, París, Gallimard, col. La Pléiade, 1967. "Que serait devenu Víctor Hugo sans l'exil, qui, en 1851, à l'orée de la cinquantaine, marque la seconde naissance du poète".

${ }^{5}$ En todo lo referente al duque de Rivas hemos consultado: Obras completas, edición de J. Campos, BAE, C-CII, 1957. Boussagnol, G., Angel de Saavedra, duc de Rivas: sa vie, son oeuvre poétique, Toulouse, Privat, 1926. Navas Ruiz, R., Imágenes liberales. Rivas, Larra, Galdós, Salamanca, Almar, 1979. 
desterrados (Pero ¿Hasta qué punto? como dice Claudio Guillén) ${ }^{6}$ y también las diferencias. ¿Qué es lo que se produce aun dentro de la evidente diferencia de dos discursos producidos uno en España y otro en Francia, uno antes y otro 29 años después?

Hemos escogido poemas pertenecientes a dos grandes obras de Víctor Hugo Les Châtiments y Les Contemplations para compararlas con algunos poemas del duque de Rivas como El faro de Malta, El desterrado, el Sueño de un proscrito y algunos otros. Hemos intentado ver si existe un paradigma común que muestre cómo los dos poetas invierten el alcance negativo del destierro para recobrar la imagen perdida de la patria y con ella la nueva identidad constituida. El exilio es doble y más aún en la época de Hugo, consciente de que «L'exil n'est pas une chose matérielle» y que el poeta es pese a todo y desde ese momento "captif de l'exil» según la magnífica fórmula hugoliana.

El carácter dual de la realidad resulta acentuado y reforzado por el estado de exilio. Ya sabemos que el carácter poético surge cuando la percepción de esta dualidad se expresa a través de la metáfora, cuando la realidad vivida por el poeta está sostenida por otra, por la imagen que se construye. La ausencia, el alejamiento, el olvido de las referencias habituales y el aislamiento hacen más agudo el doble estado interior/exterior de esta realidad.

Pero veamos si existe verdaderamente un ritual común del exilio en estos dos poetas que nos ocupan.

Conviene subrayar primeramente que ambos son a la vez sujetos y poetas de su exilio. Viven el exilio y escriben simultáneamente sobre él. En los dos casos pues, la imagen procede de una realidad externa; la realidad poética dimana de una experiencia humana vivida y sufrida con dolor ${ }^{7}$. Rivas y Hugo no expresan del mismo modo la relación que acabamos de evocar entre el yo sujeto y el yo poético, aunque en los dos casos se trate de un yo casi siempre sin referencia contextual. Es un poeta esencial y absoluto así como la imagen poetizada que el poeta quiere dar de sí mismo al lector (ver lo que dice E. Souriau al respecto) ${ }^{8}$.

Víctor Hugo es posiblemente más consciente que el duque de Rivas de

- Claudio Guillén, Entre lo uno y lo diverso, introducción a la literatura comparada, Barcelona, Editorial Crítica, 1985 , p. 32.

«... Muchos rasgos del exilio visto como cierta estructura social, política y lingüística -0 semiótica- se repiten y también hasta cierto punto sus consecuencias literarias. ¿Pero hasta qué punto? ¿Qué retos, qué réplicas, qué oportunidades, qué crisis reiteran?

7 No cabe duda que el exilio puede ser el desencadenante del texto literario, el acontecimiento que impone al sujeto la necesidad de expresar un estado de crisis pero no olvidemos que, como decia Mallarmé "c'est devant le papier que l'artiste se fait».

"Etienne Souriau citado por Jean Cohen in Structure du langage poétique, Paris, Flammarion, 1966, en el capítulo dedicado al «niveau sémantique: la détermination. Ver también E. Souriau, La correspondance des arts, París, Flammarion, 1947, y del mismo autor Les catégories esthétiques, Paris, Centre de documentation sociale. 
todo el proceso de identificación entre emisor real del mensaje y emisor poético. En el conocido prefacio a su libro Les Contemplations, Víctor Hugo alude insistentemente a esta relación antes mencionada diciendo:

«Une destinée est écrite là jour après jour.

Est-ce donc la vie d'un homme? Oui, et la vie des autres hommes aussi. Nul de nous n'a l'honneur d'avoir une vie qui soit à lui. Ma vie est la vôtre, votre vie est la mienne, vous vivez ce que je vis; la destinée est une. Prenez donc ce miroir, et regardez-vous y. On se plaint quelquefois des écrivains qui disent moi. Parlez-nous de nous, leur crie-t-on, Hélas! Quand je vous parle de moi, je vous parle de nous. Comment ne le sentez-vous pas? Ah! Insensé, qui crois que je ne suis pas toi!

Ce livre contient nous le répétons, autant l'individualité du lecteur que celle de lauteur. Homo sum. Traverser le tumuite, la rumeur, le rêve, la lutte, le plaisir, le travail, la douleur, le silence; se reposer dans le sacrifice, et, là, contempler Dieu; commencer à Foule et finir à Solitude, n'est-ce pas, les proportions individuelles réservées, l'histoire de tous?")

Esta fórmula «Ah! Insensé qui crois que je ne suis pas toi!» es célebre y Víctor Hugo ya en 1840 escribía en uno de sus poemas «chacun trouve son moi dans le moi d'un poète».

Debemos destacar la utilización frecuente de la primera persona, del «moi» presente en los poemas del exilio:

«Je t'aime exil. Douleur, je t'aime!

O cuando hace una llamada a sus compañeros los proscritos:

"O procrits, hommes de l'épreuve

mes compagnons vaillants et doux» 482. 
Pero sin embargo creemos que es el «nosotros» lo que domina en este período:

"Et nous qui serons morts, morts dans l'exil peut-être, martyrs saignants, pendant que les hommes, sans maître, vivront, plus fiers, plus beaux..."

El empleo de la tercera persona, más indeterminado, más genérico, es igualmente utilizado.

"Le poëte est pensif. A quoi donc pense-t-il?

s'est-il donc apaisé, ce captif de l'exil?"

A menudo incluso se establece un diálogo entre el poeta desterrado y su verdugo, Napoleón III que no llega a nombrar:

«Acharne toi sur l'exilé

mets l'oubli sur son nom, la nuit sur son esprit

couds ce suaire autour de ce mort, le proscrit,

spectre..."

Rivas también, como Hugo hace uso de la primera persona y expresa su sufrimiento de sujeto exiliado:

\author{
«Huyo infelice de la patria mía \\ $\ldots$ \\ mi corazón mezquino \\ se desgarra»
}

Al igual que el poeta francés el duque de Rivas utiliza también el «nosotros» pero no es el «nosotros» universal de Hugo que, en un mismo arrebato verbal abraza en su poesía del exilio a toda la humanidad proscrita (véase como ejemplo la «Oda» en la página 500). 
Esta indeterminación es igualmente notable en las indicaciones de tiempo y espacio. Víctor Hugo introduce en sus poemas nombres como Jersey y Guernesey que corresponden a espacios geográficos reales. Pero, el tiempo sin embargo es el tiempo de los proscritos, no dando ninguna precisión que lo pueda transformar en tiempo histórico. El duque de Rivas es a este respecto igualmente indeterminado, aunque aparezcan a menudo en sus poemas del destierro nombres de sitios como Córdoba, el espacio de la niñez, Malta, la isla del exilio, que le recuerda el sol de su tierra perdida, o Cádiz, último puerto antes de la separación. Pero a todos estos nombres que pertenecen a la geografia de lo real se añade toda una amalgama mitológica muy propia del Neoclasicismo. El tiempo también está presente pero no se trata tampoco de un tiempo cronológico, que pueda medirse en cifras, sino del tiempo contemplado a través del ciclo solar:

"Calma, pues, por lo menos piadoso

mientras tienda la noche su velo

hasta que arden las nubes del cielo

con los rayos del próximo sol

puede entonces tornar anheloso

aunque sea en confuso horizonte

a mirar a mi patria...”

O como en este otro ejemplo:

"Oh sol!, detén, detén, tu carro de oro..."

El azar hace que se dé una circunstancia que refuerza nuevamente y por segunda vez los rasgos comunes de su destino y de su paisaje: el duque de Rivas y Víctor Hugo están exiliados "allende los mares", en unas islas lejanas. Este itinerario geográfico confiere al elemento marino un papel importante en el universo del poeta y de su poesía ${ }^{10}$. Esto les acerca a otro exiliado, paradigma del héroe errante y sufriente que anda por el mundo lejos de su tierra de Itaca: el Ulises de la Odisea «celui qui tant erra et sur

${ }^{10}$ Véase la tesis ya antigua de J.K. Ditchy La mer dans l'oeuvre littéraire de Victor Hugo, Paris, Belles Lettres, 1925. Ver tambien Pierre Moreau y sus reflexiones acerca del «univers liquide» de V. Hugo en lo que él llama los "paisajes interiores» del poeta, p. 61 in Ames et thèmes romantiques, París, José corti, 1965. José Manuel Blecua dedicó también una antologia a la mar y a su presencia en la poesía española, El mar en la poesía española. Madrid, 1945. 
les mers passa par tant d'angoisse» tal como lo describe el texto de apertura del poema homérico".

La presencia del agua y su simbolismo en la obra de Hugo ha dado lugar a numerosos estudios. En la época del exilio las imágenes poéticas unidas al tema del agua se multiplican, pero ya años antes el poeta se dirige al océano:

\author{
"Je parle à l'océan et je lui dis c'est moi»
}

(in: toute la lyre)

Agua que corre, agua profunda, lodo, fango, todas las aguas concurren en la poesía hugoliana. Recordemos que tanto Ulises como el duque de Rivas y Hugo coinciden en un mismo tipo de viaje por mar, lo que da lugar a una misma reflexión acerca del elemento marino cargado de angustia ${ }^{12}$.

\author{
... \\ "L'eau noire, par moments accrue, \\ le navire, errante charrue \\ le flot, mystérieux sillon»
}

El agua, según la imagen poética se convierte incluso en tierra movediza, la única que le queda al proscrito.

Pierre Albouys subraya que el universo hugoliano es siempre antitético y que «au cloaque abîme répond l'espace immense»" ${ }^{13}$. No cabe duda que, en estos años sombríos dominan las imágenes negativas en las que el Imperio se describe como «bourbier, cloaque, égout».

La presencia del elemento marino es también relevante en la poesía del

"Versión francesa de la Odisea, Paris, editorial Gallimard, col. La Pléiade, 1955, p. 561.

12 "Le microcosme c'est à dire l'âme humaine est identique au macrocosme c'est à dire l'univers de la création. Prendre conscience de soi, c'est comprendre la nature, et contempler l'idéal, c'est percevoir le monde visible dans ce qu'il a de divin' dice G. Poulet in Trois essais de mythologie romantique, Paris, José Corti, 1985, p. 16. El autor recoge en parte lo que decía ya acerca de la relación entre espacio marino y descubrimiento del "yo" en Les métamorphoses du cercle, París, Flammarion, 1979, p. 176.

${ }_{13}$ Víctor Hugo, op. cit., p. XLII. 
duque de Rivas, sobre todo la del viento marino que empuja al barco lejos de la patria amada y que ruge, amenazador, como ruge también el alma del poeta. Rivas evoca en este sentido:

"El estruendo lejano de las olas

que se estrellan con hórrido bramido»

El mar no calla nunca y cuando to hace es siempre con "perfidia»:

"duerme tranquilo el mar, pérfido esconde rocas aleves, áridos escollos

-..

Siempre según el esquema marcado por Ulises, el duque de Rivas y Víctor Hugo describen en su poesía la despersonalización temporal del exiliado que expresa su necesidad de pertenecer a una comunidad y a una ciudad. No obstante parece que las dos actitudes poéticas varían en este tercer punto: Angel de Saavedra se ajusta preferentemente a los valores aristocráticos individuales mientras que Hugo reivindica su pertenencia a una nación como francés y al universo entero como poeta inspirado. Como Ulises, los dos poetas no pierden nunca en su discurso de exiliado el sentido del retorno puesto que, si escribir sobre el tema del exilio es escribir sobre la separación y el alejamiento, es también (aunque no siempre) hablar del retorno deseado ${ }^{14}$. Así nos lo determina al menos el paradigma homérico. También está vinculado al tema del retorno la constante alusión al recuerdo

${ }^{14}$ El tema del retorno deseado es ambiguo (retorno relacionado con el exilio; tomemos como ejemplo un poema de K. Kavafis, Itaca (1911) trad. española en col. Hiperión, pp. 4647.

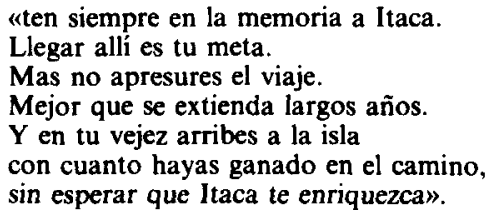


recurrente de la tierra natal que aparece idealmente en la poesía del duque de Rivas como paraíso perdido y sobre todo paraíso uterino. Hugo, en cambio, identifica la tierra a la patria, al pueblo y al trabajo.

Escribe el poeta francés:

"On ne peut pas vivre sans pain

On ne peut pas non plus vivre sans la patrie

Les exilés s'en vont pensifs

leur âme hélas n'est plus entière»

Para Hugo el exiliado es como un muerto, una sombra cuyo nombre se pierde en la noche e incluso más allá «hors du jour». Escribe en su poema «Horror»:

"Car la maison d'exil, mêlée aux catacombes,

est adossée au mur de la ville des tombes.

Le proscrit est celui qui sort;

Il flotte submergé comme la nef qui sombre.

Le jour le voit à peine et dit: Quelle est cette ombre?

Et la nuit dit: Quel est ce mort?

El duque de Rivas lamenta también la pérdida de identidad del proscrito:

"dolor y llanto y luto

es ya por siempre nuestra amarga suerte;

y sin patria y sin deudas el tributo

daremos a la muerte

siendo de ella despojos,

sin tener, ay! quien cierre nuestros ojos"

El poeta español describe su separación y su consiguiente pérdida de 
identidad en un tono menos descriptivo que Hugo. Recuerda la tierra de la niñez, el paraíso vinculado a la imagen querida de la madre y del jardín, mientras Hugo sólo acude a los vínculos adquiridos en la edad adulta a través de sus compromisos sociales y políticos.

"Madre!... Adorada madre!... Dulce nombre

que el alma arrebata y enajena y de delicias mis sentidos llenas.

No es el silbar del viento,

no es el hervir del mar, es el acento

de los objetos que mi amor implora»

Los «objetos» en Hugo se describen y están presentes, como en esta «chanson» en la que dice ${ }^{15}$.

Je meurs de ne plus voir les champs, où je regardais l'aube naître de ne plus entendre les chants que j'entendais de ma fenêtre mon âme est où je ne puis être»

La presencia del pueblo y los vínculos que unen al poeta invaden el recuerdo:

"Le poëte est pensif. A quoi donc pense-t-il?

s'est-il donc apaisé ce captif de l'exil?

non, sous ce calme front l'âme sombre est en flammes.

Il songe à tout un peuple, hommes, enfants et femmes».

15 «Qu'est-ce que l'art pur suivant la conception moderne? pregunta Baudelaire. «C'est créer une magie suggestive contenant à la fois l'objet et le sujet, le monde extérieur et l'artiste lui-même» in L'art philosophique, Les curiosités esthétiques. P. Moreau, op. cit., trata de la cuestión de la relación entre sujeto y objeto en el capítulo "paysages rétrospectifs». 
El poeta francés asume por encima de todos los exilios personales, la separación como parte inherente al ser humano en su indefectible soledad. Como ya escribía en 1846 en Toute la Lyre:

\author{
"Que se passe-t-il de terrible \\ qui fait que l'homme, esprit banni, \\ a peur de votre calme horrible \\ o ténêbre de l'infinis
}

Tanto uno como otro recuerdan a través del sueño. El Romanticismo sin embargo añade un nuevo matiz al sueño como elemento del ritual del exilio: recordar forma parte de la actividad habitual del proscrito pero esta acción adquiere entonces mayor amplitud. El sueño se convierte en viaje iniciático, experiencia risueña, acceso al paraíso perdido. Ya no se trata de rememorar con nostalgia sino de recrear e incluso de reinventar el recuerdo a la deriva. Hugo escribe «qui délivre le mot, délivre la pensée» y cuando habla de "pensamiento" o de «idea» se puede entender también «imagen»" y sobre todo imagen poética. El sueño romántico va unido a la videncia como lo indica Pierre Albouys:

"Ainsi la voyance, qui capte et émet la lumière, qui est l'oeil fixé sur Dieu et qui, en même temps, regarde et éclaire l'oeil de Dieu, la voyance qui est, dans l'espace infini, échange des regards, assure cette unité de l'être, qui est tout entier vision: Dieu est la "prunelle énorme», et voir Dieu, c'est voir l'oeil qui voit. Etre et voir ne font qu'un. L'espace est le lieu de la voyance.... ${ }^{16}$.

Esta reflexión de Pierre Albouys nos lleva al último punto del ritual que intentamos describir: la presencia de Dios invocado como responsable del castigo. Recordemos a Ulises perseguido por la cólera de los dioses del Olimpo y por Poseidón en particular. La mirada de Dios no es percibida del mismo modo por el duque de Rivas y Víctor Hugo. El poeta francés se rebela contra el destino que le impone la divinidad (véase el poema $L u x, \mathrm{p}$. 218 , III) pero acoge al dios creador de aquellos «objetos» de la naturaleza que rodean al hombre y que le permiten entrar en contacto con lo divino, con ese Dios que sabe

${ }^{16}$ Oeuvres poétiques, Victor Hugo, op. cit., pp. LXXVI. 
"créer l'araignée et sa toile peindre la fleur, mûrir le fruit et, sans perdre une seule étoile mener tous les astres la nuit»

(Lux, p. 219)

La idea de progreso ya tiende, en pleno romanticismo francés a sustituir la trascendencia de lo divino, aunque el poeta intente todavía asociar ambos procesos (en Lux, p. 222).

"Les tyrans s'éteindront comme des météores et, comme s'il naissait de la nuit deux aurores dans le même ciel bleu nous nous verrons sortir de ce gouffre où nous sommes, mêlant vos deux rayons, fraternité des hommes paternité de Dieu».

Rivas no resulta tan atrevido en su relación con Dios. Es menos exigente y no intenta confundir los dos planos que permanecen claramente separados en su poesía: un Dios inasequible y poderoso situado en un plano superior y un hombre en el plano inferior que suplica y tiene fe tal como vemos en su oda (p. 501).

"gran Dios que sabio riges

los orbes y con mano omnipotente

cuanto criaste diriges

¿No ves al inocente

perseguido...

El duque de Rivas al igual que Víctor Hugo clama contra la injusticia pero sin rebelarse del mismo modo. La libertad para los dos es algo que se reclama como un derecho del que el exiliado se siente privado al ser víctima 
de la intolerancia política ${ }^{17}$, pero para los dos poetas la libertad del discurso no puede ser la misma.

Hemos intentado abarcar aunque brevemente, el tema del exilio que a nuestro parecer se presenta como un auténtico sistema con sus variables y sus constantes. A pesar de las numerosas diferencias tanto en el discurso como en las ideas, existen, a nuestro modo de ver, una serie de etapas o pruebas que coinciden con las que debe superar también otro héroe mítico errante, el Ulises de la Odisea.

Sujetos y poetas de su exilio, rodeados por el mar y todo su simbolismo, amenazados por la pérdida de identidad, invadidos por el recuerdo, deseosos de volver a un patria que van soñando, dos poetas, el uno francés y el otro español, comparten por encima de las diferencias, un ritual común que queda plasmado en su poesía. El alejamiento, la separación, la soledad, las ansias del retorno confieren a la patria como visión poética una aura nueva que es la que rodea siempre a los espacios prohibidos.

17 Véase los Ensayos de Hölderlin en los que el autor vuelve a ofrecer una definición de la libertad tal y como lo entiende el Romanticismo. Véase también L'invention de la liberté. Jean Starobinski, Ginebra, 1964. 